\title{
Considering Cultural Consonance in Trustworthiness of Online Hotel Reviews among Generation Y for Sustainable Tourism: An Extended TAM Model
}

\author{
So Young Bae ${ }^{1}(\mathbb{D})$ and Ju Hyoung Han ${ }^{2, *}$ \\ 1 Department of Culture, Tourism \& Content, College of Hotel \& Tourism Management, \\ Kyung Hee University, 26 Kyungheedae-ro, Dongdaemun-gu, Seoul 02447, Korea; sybae@khu.ac.kr \\ 2 Department of Tourism Administration, College of Business Administration, Kangwon National University, \\ 1 Kangwondaehak-gil, Chuncheon 24341, Korea \\ * Correspondence: juhyounghan@kangwon.ac.kr
}

Received: 17 March 2020; Accepted: 4 April 2020; Published: 7 April 2020

\begin{abstract}
This study aims to predict Generation Y customers' acceptance of user-generated content (UGC) websites by integrating an extended technology acceptance model (TAM), trustworthiness of online reviews, and cultural consensus and cultural consonance theory. To collect data, a free listing method was first used to recognize our ad hoc domain, i.e., the factors that determine the trustworthiness of online hotel reviews among Generation $Y$ in South Korea, from an emic perspective. Based on the free listing results from 39 individuals, an online survey was conducted with 273 samples using a self-administered questionnaire. Cultural consensus analysis was conducted to determine whether there is a shared cultural model in trustworthiness factors among participants, and cultural consonance values were calculated. Then, a structural equation modeling technique was used to estimate how the proposed model explains the collected data. Results indicate that an agreed-upon cultural model of trustworthiness of online hotel reviews exists among sample members. Cultural consonance of trustworthiness was found to constitute a significant antecedent of perceived ease of use and attitude towards websites in the extended TAM model. This study can contribute to predict Generation Y customers' acceptance of UGC websites and offer meaningful implications for sustainable tourism management, particularly when cultural variables are considered.
\end{abstract}

Keywords: cultural consensus; cultural consonance; online hotel reviews; trustworthiness; technology acceptance model; Generation Y

\section{Introduction}

Online social media has become remarkably widespread in the hospitality and tourism industry. The emergence of Web 2.0 has led to manifold user-generated content (UGC) websites, which serve as powerful platforms for customers to spread information via word-of-mouth (WOM), seek other travelers' experiences, compare alternative products and services, and make informed purchase decisions regarding their travel planning, such as hotel selection [1]. As a result, many hospitality and tourism businesses have been utilizing UGC websites in their online business strategies.

Cost considerations constitute important elements of travel planning and decisions. Such costs include not only monetary costs, but also personal effort and time consumed in accessing necessary information and making reservations [2]. For example, individuals may perceive increased psychological barriers and costs when using UGC websites if the process of accessing useful information is cumbersome or the reservation system is not easy to use. Studies on technology adoption have primarily applied Davis' [3] Technology Acceptance Model (TAM) as a key theoretical framework, that holds that individuals' technology acceptance is determined by two cognitive constructs of a 
system, i.e., perceived usefulness and perceived ease of use. TAM has been widely applied in various disciplines, including hospitality and tourism [4-6]. Previous investigations have confirmed that the two major constructs of TAM are significant contributors to explaining customers' UGC websites adoption for travel planning $[7,8]$.

The UGC websites could be successful when customers accept Internet technologies as viable transaction methods and consider review contents as trustworthy and acceptable. Consequently, explaining decision-making processes of UGC website adoption may be highly relevant to both technology-acceptance and information-acceptance constructs. Despite the extensive applicability of TAM, a majority of the extant literature has attempted to extend existing TAM models by including additional technology-acceptance constructs, such as security [9], trust in website developers [7,10], and perceived risk [11]. However, few researchers have attempted to integrate information-acceptance constructs in their extended TAM models, particularly when explaining the adoption of UGC websites for hotel bookings.

With regard to information-acceptance constructs, the topic of trustworthiness of online review messages has attracted substantial attention in industry and academia over time. In addition, some controversial issues exist, such as deceptive online review postings in hospitality industries, e.g., some managers post promotional reviews about their business or offer benefits to customers in exchange for positive review contents [10]. The topic of trustworthiness of online reviews in travel-related UGC websites has also received a great deal of academic interest. Previous studies demonstrated that trustworthiness plays a significant role in influencing customers' attitudes and behavioral intentions toward UGC utilization in their travel-related decisions [12,13]. Despite a rising interest in trustworthiness of online reviews, however, there is limited understanding of how information-acceptance constructs (e.g., trustworthiness of online review messages) are associated with technology-acceptance constructs (e.g., perceived usefulness and perceived ease of use) that predict individuals' adoption behaviors.

Also, while existing research on trustworthiness of online reviews has examined trustworthiness as an antecedent to predict individuals' attitudes and behaviors, previous studies adopted pre-determined items to assess trustworthiness. However, such a concept of trustworthiness toward newly developed technology could have different meaning structures depending on the customer-groups examined, such as generational cohorts or cultural groups. In understanding individuals' behaviors, culture has long constituted a popular research construct. Researchers have utilized different definitions of culture, such as mental phenomena, behavioral patterns, and tangible artifacts. Cognitive anthropologists have regarded culture as information shared and taught to influence individuals' behaviors [14]. Based on this approach, Romney et al. [15] developed the theory of cultural consensus to determine whether a shared cultural model exists for a particular cultural domain. Later, the concept of cultural consonance was established to demonstrate the link between an agreed-upon cultural model and individuals' actual behaviors [16-18].

Even though the concept of cultural consonance has proven useful in understanding the relationship between a particular culture and individuals' actual behaviors, it has rarely been applied in hospitality and tourism research. Moreover, although the concept of culture has been frequently utilized, it has been primarily equated with the concept of nationality or ethnicity, and employed as a moderator to segment a group of people [19]. The trustworthiness of online reviews is certainly highly relevant to all customer groups, however, the present study focuses on Generation Y. Generation Y, referring to individuals born in between 1978 and 1994 [20], is generally technologically savvy and involved in online purchase behaviors [21]. Also, this cohort tends to travel frequently and to adopt UGC in their travel-related decision-making [22]. The advent of online social networks and their significant role in the travel industry have greatly accelerated the utilization of UGC websites among Generation $\mathrm{Y}$ as both consumers and producers of information. Indeed, establishing long-term relationships with customers has become critical in an increasing competitive online travel business, particularly for sustainable tourism management [23]. Consequently, it is imperative that hospitality 
and tourism businesses utilizing UGC websites as their fundamental online marketing strategies understand Generation Y, and develop optimal marketing strategies to target this cohort successfully.

In the present study, we adopted the concept of cultural consonance for factors used to determine the trustworthiness of online hotel reviews. The cultural consonance theory allows researchers to construct the trustworthiness of online hotel reviews with an emic approach or, from respondents' instead of researchers' perspective. This study aims to predict Generation Y customers' acceptance of UGC websites by integrating the theoretical framework of TAM, trustworthiness of online reviews, and cultural consensus and cultural consonance theory. The purpose of this study is: (1) to determine whether there is a shared cultural model of the trustworthiness of online reviews among Generation $Y$ using cultural consensus analysis (CCA) [15]; and (2) to integrate a concept of cultural consonance in trustworthiness to predict Generation Y customers' behavioral intention to adopt UGC websites for their travel planning using an extended TAM model.

\section{Literature Review}

\subsection{Generation Y and Online Travel Websites}

According to the cohort theory [24], generational cohorts facilitate further understanding of individuals' behaviors, as each cohort involves people born and grew up during the same specific period of time. Generational cohorts share similar experiences and contexts in life, which prompt each generational cohort to attain comparable attitudes, beliefs, and behaviors that remain relatively stable during one's life [24]. Brosdahl and Carpenter [25] classified generational cohorts as Baby Boomers (born between 1946 and 1960), Generation X (born between 1961 and 1981), and Generation Y (born between 1981 and 1996). Recently, researchers also used the cohort of Generation Z (born in 1997 and after) to indicate a newer generation.

While older cohorts are considered as digital immigrants, Generation Y members are innately digital natives [26]. Among the generational cohorts, Generation $Y$ is characterized as technologically savvy and more absorbed in online purchase behaviors [27]. This cohort consumes as well as produces content on social media. That is, they are simultaneously both producers and consumers of information, and tend to engage energetically in conversations via social media, such as UGC websites [28]. Due to the unique feature of social media which allows for two-way communication between users and businesses (and/or other users) [29], understanding Generation $Y$ in a social media context has become increasingly significant. In achieving this understanding, it is reasonable to understand that Generation Y's perceptions and attitudes, especially with regard to their online activities on social media and UGC websites, differ from those of other generational cohorts.

The emergence of online social media and the significant role that Generation $Y$ plays in the hospitality and tourism industries are closely connected to the distinctive characteristics of Generation Y. Generation Y prefers to spend money on experiences, travels frequently, and reviews UGC websites prior to making travel purchases [30]. Generation $\mathrm{Y}$ is also characterized as being economically robust, and has emerged as an influential consumer group with growing consumption power. Indeed, they spend USD 200 billion annually [31], and their global travel spending totals USD 136 billion annually [32]. They also constitute more than $25 \%$ of the world's population, and they are highly sociable and tech-literate [33,34]. Due to these characteristics, it is a paramount goal for marketers and managers of online travel websites to thoroughly understand this cohort member's travel-related online customer behaviors [21,35].

Nusair et al. [21] explains how Generation $Y$ in the U.S. develops commitment to an online travel website vendor, and shows that commitment is a key factor in developing and maintaining long-term relationships with Generation Y. Bilgihan [35] reports that the features of hotel booking websites and customer trust are primary antecedents of e-loyalty for Generation $Y$ customers. Bento et al. [36] showed that Generation Y, compared to Generation X, in Portugal, consumed more content on social media pages and were more likely to possess an e-WOM intention. Indeed, the extant literature has 
demonstrated that Generation $\mathrm{Y}$ and the use of social media are inseparable [21,35]. To consider the extensive influence of digital technology environments on digital natives' behaviors, the current study discusses online travel website adoption behaviors targeting Generation $\mathrm{Y}$ in South Korea.

\subsection{Online Review Trustworthiness}

When individuals assess information, they judge the credibility of the information depending on beliefs about the source, the message, the medium, and the information providers $[37,38]$. Trustworthiness is one of the most important dimensions (e.g., authenticity, transparency, fairness, accuracy) that information-seekers use to evaluate information credibility [13,38]. Unlike offline WOM, which is based on face-to-face communication, e-WOM communication on UGC websites exhibits no direct or prior relationships with information providers [39]. This may obstruct individuals in relying upon the trustworthiness of online review messages. Therefore, in order to accurately assess trustworthiness, customers attempt to utilize other cues, such as characteristics of messages, and reviewers' geographical locations, demographics, and previous experiences [40].

Previous investigations have attempted to identify how customers evaluate online reviews as being trustworthy. Cheung et al. [41] showed that source credibility, confirmation of prior beliefs, recommendation consistency, recommendation ratings, and argument strength influence the trustworthiness of online review messages. In addition, Qiu et al. [42] found that a conflicting aggregated rating decreased review trustworthiness. Kusumasondjaja et al. [43] empirically demonstrated that a negative review is perceived as more trustworthy than a positive review when the posting reveals the identity of the reviewer. Nevertheless, when the reviewer's identity was not disclosed, there was no significant difference in trustworthiness between positive and negative reviews [43].

The findings of the abovementioned investigations imply that customers' strategies to appraise the level of trustworthiness of messages vary, and individuals do not assign equal evaluations of trustworthiness to online review messages. Nevertheless, online review trustworthiness in previous literature is studied with pre-existing scales or universally operationalized constructs, which may differ depending on cultural customer groups or generational cohorts. Little research has considered the existence of a cultural disposition towards trustworthiness and its effects on online travel website adoption behavior. From an information-seeker's perspective, culturally shared beliefs about online review trustworthiness provide an important cue for them to evaluate UGC websites in their travel-related decision-making process. The present investigation seeks to examine cultural consonance in online review trustworthiness among Generation Y members, and then assess whether it plays a significant role in UGC website adoption for their travel planning.

\subsection{Cultural Consensus and Cultural Cononance}

Culture is defined as "whatever it is one has to know and believe to operate in a manner acceptable to members" [44] (p. 167). In cognitive anthropology, culture has often been considered as a set of information that shared and taught in a society which affects human behaviors [14,45]. In this context, anthropologists have explored cultural domains, indicating "a set of items that are all of the same type" which exist in line with culture [46] (p. 1).

Among cultural domains, there are explicit domains, such as "animals" or "flowers", as well as implicit domains, also called ad hoc domains, such as "the things to use for baking" or "qualifications to become a competitive researcher" [47]. Ad hoc domains are goal-derived in nature and often comprise highly specified contexts. Moreover, researchers analyze a particular cultural domain from cultural insiders' perspectives rather than their own [48]. Free listing is one of the preferred methods to determine the content of a domain [46]. It requires respondents to list all of the items that they believe fit into a given domain.

The idea of cultural consensus was developed as a theory and a method to assess intracultural differences in a single cultural domain [15]. CCA is employed to determine the degree to which individuals have agreement on the substance of specific knowledge domains. It offers "culturally 
correct answers" to questions about a given domain [49] (p. 339), and indicates the existing level of variability in cultural sharing among cultural insiders [15,50]. Although CCA originated in cultural anthropology, it has been frequently employed in other disciplines, such as medicine [51], sociology [52], and gerontology [53].

Researchers in tourism and leisure studies have also applied CCA in their research. For example, Ribeiro and Yarnal [54] investigated whether there was an agreed cultural model concerning perceptions of spring breakers among college students in the U.S. Kerstetter et al. [55] also discussed the sense of place among Fijian highlanders. Recently, Bae and Chick [56] studied a domestic rail travel phenomenon among the young generation in Korea, called Rail-ro. In this study, Rail-ro experiences were determined as a coherent culture among travelers who undergo Rail-ro experiences.

Dressler and colleagues later attempted to extend CCA [16-18]. Specifically, they included the concept of cultural consonance, which refers to the degree to which individual behavior is in line with the existing cultural model for that particular behavior [16]. Cultural consonance analysis (CCOA) deals with the association between the agreed-upon cultural model and individual beliefs and behaviors [17]. In their research, they mainly examined the influence of cultural consonance with regards to individuals' lifestyle, social support, family life, and national identity on psychological and physical health outcomes (e.g., stress level, depressive symptoms, blood pressure) $[17,18]$.

CCoA has considerable merit in understanding the nature and effects of a particular cultural domain in a specific cultural context [57]. Chick and colleagues applied this concept in their investigation of leisure behaviors. The results of their study, using the concept of cultural consonance in leisure, indicated that cultural consonance with respect to leisure activities to a good leisure life positively influenced leisure satisfaction, life satisfaction, and self-reported health [58,59]. In their subsequent study, they also determined that cultural consonance mediates the relationship between leisure constraints and leisure satisfaction [57].

Despite the utility of the concept of cultural consonance in elucidating the link between a particular culture and individuals' actual behaviors, it has rarely been implemented in the field of hospitality and tourism. The primary focus of the present study is to examine the following ad hoc cultural domain: "the factors that determine the trustworthiness of online hotel reviews among Generation $\mathrm{Y}$ in South Korea." Cultural consonance for this domain indicates the degree to which individuals behave in accordance with a cultural model of the importance of a set of elements to determine the trustworthiness of online hotel reviews. In this study, cultural consonance was considered as a possible antecedent to other meaningful variables in analyzing attitudes or behaviors of a particular cultural group.

\subsection{Extended TAM}

In 1985, Fred Davis initially introduced TAM, which postulates that: (1) behavioral intention to adopt new technology is affected by attitude; and (2) attitude is influenced by two technology-related constructs, i.e., perceived ease of use and perceived usefulness. This model was developed based on the Theory of Reasoned Action [60]. In TAM, perceived ease of use and perceived usefulness are included as belief constructs in predicting attitude and behavioral intention. TAM stands out as a parsimonious and effective model for explaining users' technology adoption behavior [7,61], and assists researchers and practitioners to determine the acceptance of a particular technology or system.

Studies employing TAM have demonstrated substantial empirical support for explaining individuals' acceptance of technology, such as smart phones, technology-based services, and new media $[4,62]$. In tourism and hospitality literature, TAM has also been applied to explore employees' acceptance of technology, such as hotel front office systems [5], travel agency computerized reservation systems [6], biometric system adoption in hotels [63], and restaurant computing systems [64].

While this model was initially applied to system usage in the workplace, researchers have used it to understand individual customers' website use [8,11] and intention to shop travel online [65]. The findings of these previous studies consistently showed that perceived ease of use, perceived usefulness, and 
attitude are significant determinants of users' acceptance of technology-related applications. For example, previous findings supported significant correlations between trustworthiness and the aforementioned determinants. Ayeh [61] demonstrated that trustworthiness has a positive effect on the usefulness of, and attitudes toward, consumer-generated media adoption for travel planning. Pavlou [8] showed that, in a B2C e-commerce context, trustworthiness exerts a positive effect on perceived ease of use and perceived usefulness. Furthermore, Xie et al. [66] and Chircu et al. [67] agreed that perceived ease of use and perceived usefulness are positively affected by trustworthiness. The findings of these empirical studies supported the existence of positive associations between trustworthiness, perceived ease of use, perceived usefulness, and attitude.

Researchers have found that trustworthiness increases perceived ease of technology usage because trustworthiness assists the customer to understand, monitor, and control situations or web retailer's actions, and thus facilitates the transaction and makes the process effortless $[8,67]$. Researchers also demonstrated that trustworthiness is an important determinant of perceived usefulness [8]. This is partly because customers would expect to obtain usefulness from a website if they believe the people behind the website or trust the information provided via the website. In other words, if a website's contents are not trusted to behave in line with the customers' beliefs and expectations, then customers will not anticipate obtaining any utility from using the website or develop positive attitudes toward it.

Based on the wide applicability of TAM, researchers have attempted to extend the model by adding more determinant factors in order to augment the model's predictive power [68]. In the hospitality and tourism context, a popular area has been understanding website acceptance for customer decision-making. For example, Ayeh [61] conducted an online survey in Singapore, and found that perceived ease of use and perceive usefulness, other than source credibility, in an extended TAM model, play significant roles in explaining attitude and intention to use TripAdvisor. Agag and El-Masry [11] developed an extended TAM model by including a website's characteristics (e.g., perceived ease of use and perceived usefulness), company's characteristics (e.g., website reputation), and customer's characteristics (e.g., customer experience), and showed that the additional variables further help to explain users' attitudes toward online travel websites in Egypt. In the present study, we attempt to develop an extended TAM model by adding the variable of cultural consonance in online review trustworthiness to further understand adoption behavior of UGC websites for travel planning.

\subsection{Research Model}

The value of TAM in a technology-acceptance context has been widely demonstrated, and employing it in the context of UGC website adoption behavior in travel-related decision-making processes is theoretically and empirically supported. Considering the importance of understanding the link between a particular culture and individuals' actual behaviors, it is also reasonable to add a cultural variable in the information-acceptance context, i.e., cultural consonance in online review trustworthiness, in an extended TAM model. Drawing upon the findings and theories of the previous literature reviewed above, this paper attempts to theoretically develop and empirically validate a research model that predicts travelers' acceptance of UGC websites among Generation Y in South Korea. The following is a proposed research model with 10 research hypotheses (Figure 1): 


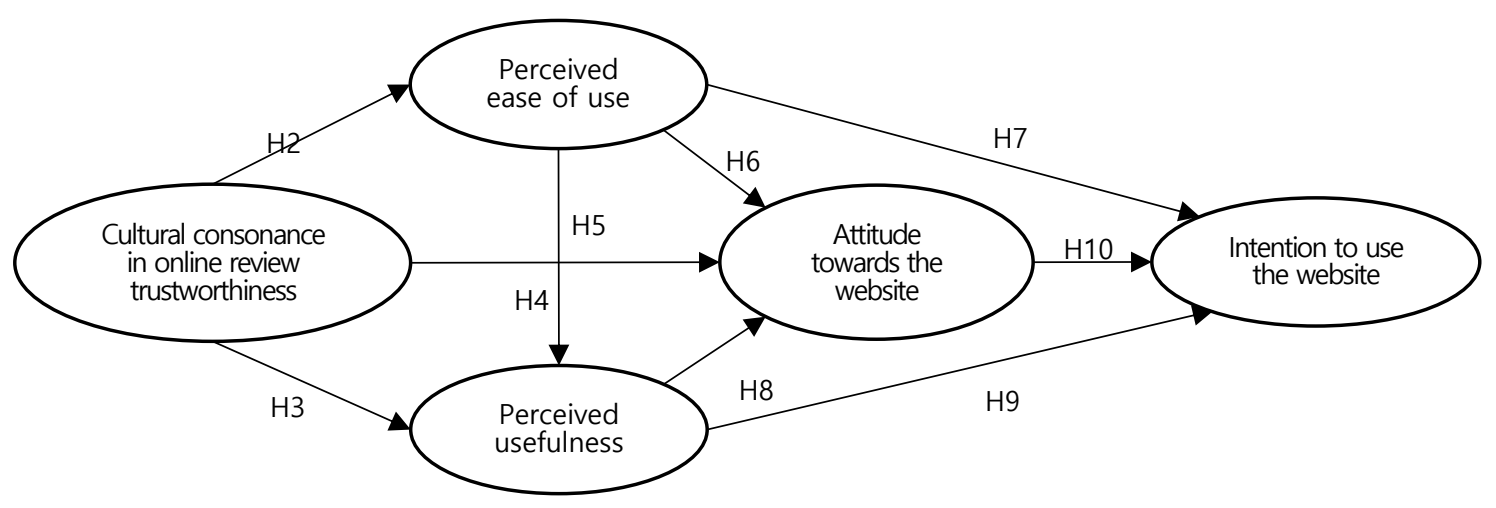

Figure 1. The proposed research model.

Hypothesis 1 (H1). An agreed-upon cultural model of online hotel review trustworthiness exists among Generation $Y$ in Korea, i.e., a cultural consensus exists with regard to the degree of importance of elements for online hotel review trustworthiness.

Hypothesis 2 (H2). Cultural consonance in online hotel review trustworthiness positively influences perceived ease of use.

Hypothesis 3 (H3). Cultural consonance in online hotel review trustworthiness positively influences perceived usefulness.

Hypothesis 4 (H4). Cultural consonance in online hotel review trustworthiness positively influences attitude towards the website.

Hypothesis 5 (H5). Perceived ease of use positively influences perceived usefulness.

Hypothesis 6 (H6). Perceived ease of use positively influences attitude towards the website.

Hypothesis 7 (H7). Perceived ease of use positively influences intention to use the website.

Hypothesis 8 (H8). Perceived usefulness positively influences attitude towards the website.

Hypothesis 9 (H9). Perceived usefulness positively influences intention to use the website.

Hypothesis 10 (H10). Attitude towards the website positively influences intention to use the website.

\section{Methods}

\subsection{Data Collection}

We collected the data in two phases in this study. We first used a free listing method to recognize our ad hoc domain, i.e., the factors that determine the trustworthiness of online hotel reviews among Generation Y in South Korea, from an emic perspective. Based on the free listing results, an online questionnaire was distributed to a larger sample.

First, the free listing method was applied. The free listing method is a useful ethnographic method to collect possible items which can be members of a particular cultural domain by asking respondents to provide as many items as possible that they would include in the given cultural domain $[46,69]$. At this stage, we administered a free listing that targeted young Korean domestic travelers who have made a purchase decision based on online hotel reviews from hotel reservation websites or applications. 
We asked respondents to make a list of all of the factors which they believe were important to consider when determining whether or not online hotel reviews were trustworthy. We also included a minimal level of demographic information, i.e., such as gender and age.

Considering the acceptable sample size of 30 for free listing in general [70], our lists from 39 individuals were sufficient. Our lists provided a total of 32 items, but we finally used 21 items to measure cultural consonance after rewording, clarifying, or removing items (Table 1). For example, we combined items which included the same meaning, but in a different wording. We also split items into two, which included more than two meaning constructs within a single item.

Table 1. Final items for the trustworthiness of online hotel reviews.

\begin{tabular}{|c|c|}
\hline \multicolumn{2}{|c|}{ Whether __ Is Important for Trustworthy Online Hotel Reviews. } \\
\hline 1. & a reviewer is the person who actually stayed at a hotel \\
\hline 2. & a review was written frankly \\
\hline 3. & a review includes points in which I am interested (e.g., cleanliness, accessibility) \\
\hline 4. & a review was written objectively \\
\hline 5. & a review includes a detailed explanation about facilities \\
\hline 6. & a review was written recently \\
\hline 7. & there are consistent comments about a particular accommodation \\
\hline 8. & a review includes negative aspects \\
\hline 9. & there are a number of reviews for a particular accommodation \\
\hline 10. & a review was written sincerely \\
\hline 11. & a review includes photos taken by the reviewer \\
\hline 12. & review comments are aligned with the current reputation of the accommodation \\
\hline 13. & a review was written from a balanced perspective \\
\hline 14. & review comments are aligned with a current rating of the accommodation \\
\hline 15. & the website manager had consistent and interactive communication with users \\
\hline 16. & the website has a good reputation \\
\hline 17. & a review was written in an expected length \\
\hline 18. & a review displays personal information about reviewers (e.g., age, gender) \\
\hline 19. & a reviewer's purpose of his or her trip is similar to mine \\
\hline 20. & a review includes personal travel stories \\
\hline 21. & a reviewer has rich travel experiences \\
\hline
\end{tabular}

Second, an online questionnaire was developed based on the free listing result. It was then distributed to online panels of one of the major online survey companies in Korea from August 3, 2017 to August 21, 2017. The study population included: (1) Korean college students; (2) who currently reside in Seoul or neighboring areas (i.e., Kyunggi and Incheon); and (3) have reserved a room based on online hotel reviews from hotel reservation websites or applications for a domestic trip. A total of 400 responses were received, and 273 responses were used for analysis after removing missing and irrelevant data for CCA.

To measure our first construct, cultural consonance, we included two sets of questions with regards to our 21 items derived from the free listing: (1) how important each item is to produce trustworthiness of online reviews (importance); and (2) how much each item was referred to in their recent decision-making concerning a hotel reservation (frequency). Next, we developed measurements for the four constructs in TAM based on Davis [3]. Perceived ease of use was defined as the degree to which an individual believes that using a hotel reservation website or application will be effort-free, and was measured using four items (e.g., It is easy to explore this website). Perceived usefulness was defined as the degree to which an individual believes that using a hotel reservation website or application will improve one's performance, and was assessed using four items (e.g., This website helps me save time in booking accommodations). Attitude towards the website was defined as an individual's preposition toward the website, and was measured using four items (e.g., I felt comfortable in exploring the website). Intention to use the website was defined as the level of satisfaction with the website and intention to revisit it, and was assessed using four items (e.g., I am satisfied with the 
service provided by this website). All of the items for the five constructs above were measured using a 5-point Likert-type scale (1: extremely disagree; 5: extremely agree).

Prior to asking a series of questions about these five constructs, we asked respondents to name a hotel reservation website or application that they have used recently in order to remind them of their purchase experience. At the conclusion of the survey, we requested certain demographic information, such as gender, age, school year, education, and frequency of using online hotel reviews. Prior to distributing the survey, two professionals reviewed the questionnaire for clarity and completeness. Then, we administered a pilot survey targeting 100 respondents in order to receive feedback concerning the length and flow of the questionnaire, as well as to identify and correct errors.

\subsection{Data Analysis}

A series of data analyses were conducted using SPSS 23.0 and Amos 20. First, to confirm whether a shared cultural model exists for the ad hoc domain, "factors that determine the trustworthiness of online hotel reviews among Generation Y in South Korea," we used a CCA based on the guideline in Chick et al. [57]. Using SPSS 23.0, we first randomized the data with regards to the importance question (i.e., how important each item is to produce trustworthiness of online reviews), and transposed the data matrix from rows (cases) to columns (variables), and from columns to rows. We then ran multiple factor analyses using principal axis factoring to obtain a stable solution, since CCA inherently includes a much greater number of columns than rows when the sample size is large. In this study, we ran factor analysis 39 times using seven columns at a time. We also calculated culturally correct answers (i.e., cultural answer keys) by weighting the answers of each informant by their competence scores and averaging the values [49]. Second, upon the existence of the agreed-upon cultural model of online hotel review trust, we calculated cultural consonance scores. We summed all respondents' importance ratings for each of the 21 items, and created sample level importance values. Next, we correlated the frequency values of each respondent with the agreed-upon importance scores. When a respondent reported a frequent consideration of the particular trustworthiness item that was agreed-upon as being important, the result exhibited higher positive correlations, representing high cultural consonance. Third, we ran structural equation modeling using Amos 20 to analyze the data based on the five variables, including cultural consonance calculated in the earlier step. Based on the two-step analysis [71], confirmatory factor analysis (CFA) was conducted first to confirm the measurement of each scale and fit the measurement model. We then ran SEM to test hypothesized relationships among latent variables in the research model.

\section{Results}

\subsection{Sampmle Characteristics}

Table 2 presents the profile of the samples. Of all 273 respondents, $53.8 \%$ were females. Their age ranged from 19 to 26 , with slightly higher proportions of $22(19.0 \%)$ and $23(23.1 \%)$ than the other ages. The sample included more juniors and seniors than freshmen and sophomores. A majority of them $(91.4 \%)$ were four-year university students. All respondents answered that they refer to online reviews when planning to travel, while the frequency varied from sometimes to always. Approximately half of the respondents (47.6\%) responded that they always refer to online reviews in their travel planning.

\subsection{Cultural Consensus and Cultural Consonance Analysis}

We ran CCA on our ad hoc domain, "factors that determine the trustworthiness of online hotel reviews among Generation $\mathrm{Y}$ in South Korea." The ratio of the average value for the first (mean = 3.69) and second eigenvalues (mean $=1.12$ ) was 3.29, which is above the threshold (three-to-one ratio). The first factors represented an average of $52.83 \%$ of the variance, and the average of the first factor loading was 0.66 . None of the 39 analyses contained negative factor loadings. According to Romney et al. [15], these values met the guidelines for a single factor solution. Therefore, the result indicates that 
sample members share a cultural model of the relative importance of online hotel review trustworthiness. This result supports H1-that an agreed-upon cultural model of trustworthiness in online hotel reviews exists among Generation Y in South Korea. Cultural answer keys are listed in Table 3.

Table 2. Socio-demographic characteristics of respondents.

\begin{tabular}{|c|c|c|c|c|c|c|c|}
\hline \multicolumn{2}{|c|}{ Characteristics } & \multirow{2}{*}{$\begin{array}{c}\mathbf{N} \\
126\end{array}$} & \multirow{2}{*}{$\begin{array}{c}\% \\
46.2\end{array}$} & \multicolumn{2}{|c|}{ Characteristics } & \multirow{2}{*}{$\begin{array}{l}\mathbf{N} \\
27\end{array}$} & \multirow{2}{*}{$\begin{array}{c}\% \\
9.9\end{array}$} \\
\hline Condor & Male & & & \multirow{4}{*}{ Year } & Freshman & & \\
\hline Gender & Female & 147 & 53.8 & & Sophomore & 55 & 20.1 \\
\hline \multirow{8}{*}{ Age } & 19 & 20 & 7.3 & & Junior & 88 & 32.2 \\
\hline & 20 & 21 & 7.7 & & Senior & 103 & 37.7 \\
\hline & 21 & 40 & 14.7 & \multirow{2}{*}{ Education } & Two-year college & 23 & 8.6 \\
\hline & 22 & 52 & 19.0 & & Four-year university & 246 & 91.4 \\
\hline & 23 & 63 & 23.1 & Frequency of & Sometimes & 29 & 10.8 \\
\hline & 24 & 31 & 11.4 & referring to online & Often & 111 & 41.3 \\
\hline & 25 & 31 & 11.4 & reviews & Always & 128 & 47.6 \\
\hline & 26 & 14 & 5.5 & Total & & 273 & 100.0 \\
\hline
\end{tabular}

Table 3. Cultural answer keys of each item.

\begin{tabular}{|c|c|c|c|}
\hline & Items & Score & Rank \\
\hline \multicolumn{4}{|c|}{ Whether __ is important for trustworthy online hotel reviews. } \\
\hline 1. & a reviewer is the person who actually stayed at a hotel & 4.54 & 1 \\
\hline 2. & a review was written frankly & 4.49 & 2 \\
\hline 3. & $\begin{array}{l}\text { a review includes the points in which I am interested } \\
\text { (e.g., cleanliness, accessibility) }\end{array}$ & 4.46 & 3 \\
\hline 4. & a review was written objectively & 4.37 & 4 \\
\hline 5. & a review includes a detailed explanation about facilities & 4.25 & 5 \\
\hline 6. & a review was written recently & 4.16 & 6 \\
\hline 7. & $\begin{array}{l}\text { there are consistent comments about a } \\
\text { particular accommodation }\end{array}$ & 4.15 & 7 \\
\hline 8. & a review includes negative aspects & 4.15 & 8 \\
\hline 9. & there are a number of reviews for a particular accommodation & 4.04 & 9 \\
\hline 10. & a review was written sincerely & 4.04 & 10 \\
\hline 11. & a review includes photos taken by the reviewer & 3.93 & 11 \\
\hline 12. & $\begin{array}{l}\text { review comments are aligned with the current reputation of } \\
\text { the accommodation }\end{array}$ & 3.92 & 12 \\
\hline 13. & a review was written from a balanced perspective & 3.84 & 13 \\
\hline 14. & $\begin{array}{l}\text { review comments are aligned with the current } \\
\text { rating of the accommodation }\end{array}$ & 3.82 & 14 \\
\hline 15. & $\begin{array}{l}\text { the website manager had consistent and interactive } \\
\text { communication with users }\end{array}$ & 3.69 & 15 \\
\hline 16. & the website has a good reputation & 3.50 & 16 \\
\hline 17. & a review was written in an expected length & 2.96 & 17 \\
\hline 18. & $\begin{array}{l}\text { a review displays personal information about the reviewers } \\
\text { (e.g., age, gender) }\end{array}$ & 2.95 & 18 \\
\hline 19. & a reviewer's purpose of his or her trip is similar to mine & 2.71 & 19 \\
\hline 20. & a review includes personal travel stories & 2.66 & 20 \\
\hline 21. & a reviewer has rich travel experiences & 2.33 & 21 \\
\hline
\end{tabular}

Since the results demonstrated that there is cultural consensus for our ad hoc domain, we proceeded to calculate cultural consonance values. We ran a correlation analysis with the two sets of data, i.e., importance and frequency values for the 21 items in our ad hoc domain. Then, the calculated value was added to the extended TAM as a new variable. 


\subsection{Measurement Model}

To assess the overall measurement model, CFA was conducted (Table 4). The measurement model test showed a good fit to the data $\left(\chi^{2}=199.538, \mathrm{df}=105, p=0.000, \mathrm{CFI}=0.955, \mathrm{NFI}=0.911, \mathrm{IFI}=\right.$ 0.956, SRMR $=0.049$, RMSEA $=0.058$ ). The Cronbach's alpha values of the four constructs were above 0.7 , which confirms the reliability of internal consistency [72]. The values for composite reliability (CR) and average variance extracted (AVE) were above the threshold of 0.7 and 0.5 , respectively, which demonstrates construct reliability and convergent validity [73]. Discriminant validity was also confirmed since the square root of the AVE was greater than each correlation coefficient [74] (Table 5).

Table 4. Confirmatory factor analysis of constructs and indicators.

\begin{tabular}{|c|c|c|c|c|}
\hline Constructs and Indicators & Loading & t-Value & AVE & CR \\
\hline Perceived ease of use $(\alpha=0.815)$ & & & 0.705 & 0.903 \\
\hline PEOU1: It is easy to explore this website. & 0.598 & - & & \\
\hline $\begin{array}{l}\text { PEOU2: It is easy to find the accommodation } \\
\text { that I want from this website. }\end{array}$ & 0.679 & 11.116 & & \\
\hline $\begin{array}{l}\text { PEOU3: It is not difficult to make reservations } \\
\text { and payments on this website. }\end{array}$ & 0.708 & 8.983 & & \\
\hline $\begin{array}{l}\text { PEOU4: Overall, this website is easy to use. } \\
\text { Perceived usefulness }(\alpha=0.746)\end{array}$ & 0.880 & 10.046 & 0.670 & 0.890 \\
\hline $\begin{array}{l}\text { PU1: This website helps me to save time to } \\
\text { book accommodation. }\end{array}$ & 0.652 & - & & \\
\hline $\begin{array}{l}\text { PU2: This website helps me save money to } \\
\text { book accommodation. }\end{array}$ & 0.574 & 7.716 & & \\
\hline $\begin{array}{l}\text { PU3: This website helps me to lessen the } \\
\text { difficulties of booking accommodation. }\end{array}$ & 0.644 & 8.445 & & \\
\hline $\begin{array}{l}\text { PU4: Overall, this website is useful to } \\
\text { book accommodation. }\end{array}$ & 0.711 & 9.076 & & \\
\hline Attitude towards the website $(\alpha=0.833)$ & & & 0.702 & 0.903 \\
\hline Att1: I felt comfortable exploring the website. & 0.850 & - & & \\
\hline Att2: I had a good time exploring the website. & 0.779 & 14.094 & & \\
\hline $\begin{array}{l}\text { Att3: This website helped me to become } \\
\text { familiar with this online booking company. }\end{array}$ & 0.648 & 11.095 & & \\
\hline $\begin{array}{l}\text { Att4: Compared to other websites, this website } \\
\text { is excellent. }\end{array}$ & 0.660 & 11.503 & & \\
\hline Intention to use the website $(\alpha=0.851)$ & & & 0.745 & 0.921 \\
\hline $\begin{array}{c}\text { Int1: I am satisfied with the service provided } \\
\text { by this website. }\end{array}$ & 0.688 & - & & \\
\hline $\begin{array}{c}\text { Int2: I would like to visit this website again in } \\
\text { the future. }\end{array}$ & 0.701 & 10.045 & & \\
\hline Int3: I will use this website with no hesitation. & 0.831 & 11.746 & & \\
\hline $\begin{array}{l}\text { Int4: I will consider this website first for future } \\
\text { accommodation booking. }\end{array}$ & 0.799 & 11.483 & & \\
\hline
\end{tabular}

Note: $\chi^{2}=199.538, \mathrm{df}=105, p=0.000, \mathrm{CFI}=0.955, \mathrm{NFI}=0.911, \mathrm{IFI}=0.956, \mathrm{SRMR}=0.049, \mathrm{RMSEA}=0.058$.

Table 5. Correlations among latent constructs, means, and standard deviations (SD).

\begin{tabular}{|c|c|c|c|c|c|c|c|}
\hline Construct & \multicolumn{5}{|c|}{ Correlation of Constructs } & Mean & SD \\
\hline (1) Cultural consonance & - & 0.239 & 0.186 & 0.285 & 0.199 & 3.694 & 0.419 \\
\hline (2) Perceived ease of use & 0.239 & 0.824 & 0.476 & 0.685 & 0.606 & 3.947 & 0.542 \\
\hline (3) Perceived usefulness & 0.186 & 0.476 & 0.803 & 0.488 & 0.545 & 3.958 & 0.442 \\
\hline (4) Attitude & 0.285 & 0.685 & 0.488 & 0.829 & 0.649 & 3.723 & 0.577 \\
\hline
\end{tabular}

Note: Values on the diagonal are the square roots of average variance extracted. For adequate discriminant validity, diagonal elements should be greater than corresponding off-diagonal elements. $p<0.05$. 


\subsection{Structural Model}

The results indicate that the data are sufficiently explained by the proposed structural model $\left(\chi^{2}=199.509, \mathrm{df}=106, p=0.000, \mathrm{CFI}=0.956, \mathrm{NFI}=0.911, \mathrm{IFI}=0.956, \mathrm{SRMR}=0.048, \mathrm{RMSEA}=0.057\right)$. As shown in Figure 2, cultural consonance indicated significant positive influence on perceived ease of use $(\beta=0.20, p<0.001)$ and attitude towards the website $(\beta=0.12, p<0.001)$, supporting $\mathrm{H} 2$ and $\mathrm{H} 4$. However, there was no significant influence between cultural consonance and usefulness, which rejects H3. Perceived ease of use showed a significant positive influence on perceived usefulness ( $\beta=0.60, p<0.001$ ), which supports H5. Both perceived ease of use and perceived usefulness were significant antecedents for attitude towards the website $(\beta=0.69, p<0.001 ; \beta=0.17, p<0.001)$, which supports $\mathrm{H} 6$ and $\mathrm{H} 8$. Finally, intention to use the website was significantly affected by perceived ease of use $(\beta=0.22, p<0.001)$, perceived usefulness $(\beta=0.37, p<0.001)$, and attitude towards the website $(\beta=0.35, p<0.001)$, which supports H7, H9, and H10.

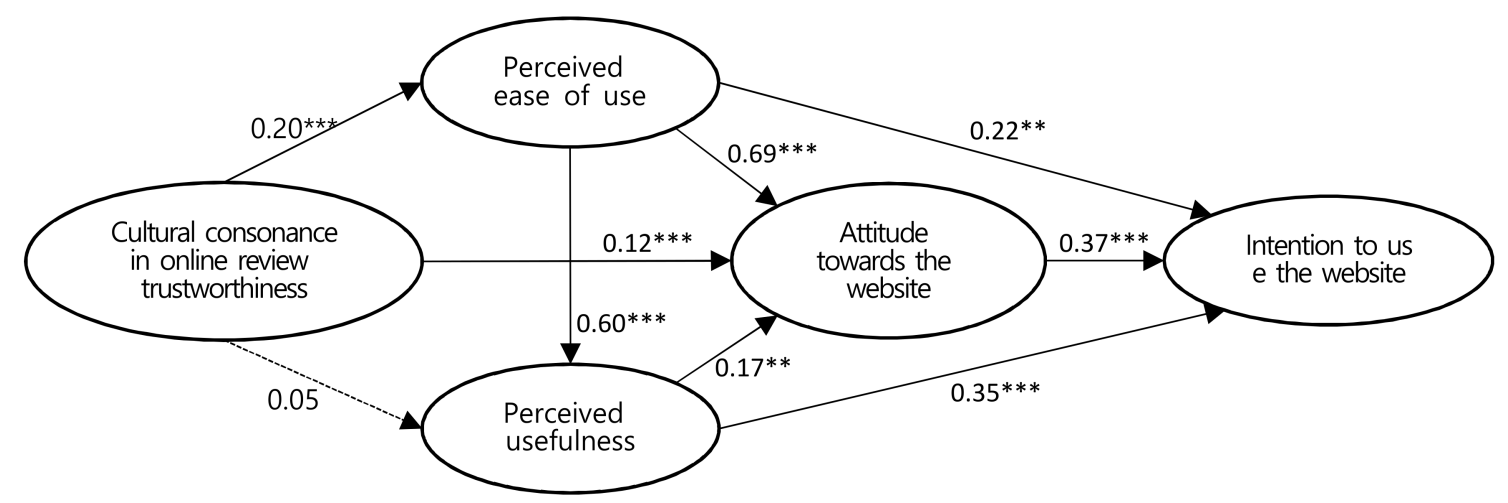

Figure 2. The estimated structural model. Notes: $\chi^{2}=199.509, \mathrm{df}=106, p=0.000, \mathrm{CFI}=0.956, \mathrm{NFI}=$ 0.911 , IFI $=0.956$, SRMR $=0.048$, RMSEA $=0.057 ;{ }^{* *} p<0.01 ;{ }^{* * *} p<0.001$; two-tailed test, standardized coefficient; solid line: significant path; dotted line: non-significant path.

\section{Discussion and Conclusions}

In order to consider the substantial influence of Generation $Y$ on the hospitality and tourism sectors, this study's results help to predict Generation Y customers' acceptance of UGC websites and offer meaningful implications, particularly when cultural consensus and cultural consonance are taken into account.

According to the CCA, the result indicates that a cultural model of the importance of trustworthiness toward online hotel reviews did exist among the sample members, which supports H1. In other words, there was an agreed-upon cultural model for our ad hoc domain (i.e., the importance of trustworthiness in online hotel reviews) among Generation Y. While previous studies have reported various antecedents of trustworthiness of online hotel reviews (e.g., the reviewer's identity, review valence, and reader-reviewer similarity), this study offered the culturally correct answers (i.e., cultural answer keys) for trustworthiness among Generation Y using the CCA. The results demonstrated that reviews which were written honestly and objectively were ranked high, whereas reviewers' travel career or personal travel stories were not considered important. It is plausible to conclude that reviewers' travel history did not strongly appeal to Generation $\mathrm{Y}$ because travel has now become universal and de-exoticized, i.e., travel is not perceived as being an activity that is exclusive to a limited population [75]. In addition, considering the abundance of experience and information, sometimes being commercialized, respondents might want to seek multi-criteria and multi-person information from objectively written reviews to obtain more robust information [76].

Based on the CCA, this investigation assessed the link between the agreed-upon cultural model and individual behaviors using the concept of cultural consonance. When cultural consonance was added as an extended variable in the TAM model, the results indicate that cultural consonance exerts a 
significant positive influence on perceived ease of use, which supports H2. Individuals use various trustworthiness cues to evaluate websites [40]. Specifically, when Generation Y in South Korea referred to particular trustworthiness factors which were considered to be important by other members in the cultural group, he or she perceived that it was easy to navigate the website and find his or her desired accommodation. In this study, culture is assumed to be highly important in an individual's evaluation of the website. This is partly in line with the finding in Sohaib and Kang [77] that opinions from social media cues are more strongly referred to in building trust towards a website in a collectivistic culture than in an individualistic society. However, cultural consonance did not significantly affect perceived usefulness, which led us to reject $\mathrm{H} 3$. Although an individual considered certain trustworthiness factors which were deemed important by his or her peers in the cultural group, it was not necessarily related to saving time or money when reserving a room. It is possible that consumers might evaluate whether the reviews are trustworthy and the usefulness of the website differently. In other words, despite the trustworthiness of the reviews shared among cultural group members, individuals could consider the website as either useful or useless when making a final reservation and payment decision on the UGC websites.

Cultural consonance positively affected attitude towards the website, which confirms H4. When respondents referred to particular trustworthiness factors considered important in their cultural in-group, they felt comfortable, enjoyed navigating the website, and perceived that the website is excellent. It has been shown that attitude towards the website is improved when perceived risk becomes minimal [78]. In this study, culture matters in determining attitude towards the website. Specifically, it could be possible that the congruence between culturally shared beliefs and individual behaviors (i.e., cultural consonance) helps people to minimize perceived risk. While previous studies have confirmed that trustworthiness of online reviews boosts attitude towards the website, culture per se (i.e., cultural consonance of trustworthiness) also contributes to predict people's behaviors [79].

All of the relationships among the existing variables in the TAM model received strong support. Specifically, perceived ease of use of a website exerted a significant positive influence on perceived usefulness, attitudes towards the website, and intention to use the website, which supports H5, H6, and H7. Perceived usefulness was a significant antecedent of attitude towards the website and intention to use the website, which supports H8 and H9. Attitude also predicted the intention to use the website, which supports H10. This study result is in accordance with those of previous studies in which attitude towards the website was tested based on TAM, such as Agag and El-Masry [11], Pavlou [8], and Wu et al. [80].

This study has contributed to expanding the understanding of Generation $Y$ customers' acceptance of UGC websites. It is meaningful that, in this study, the trustworthiness factor was examined from an emic perspective (i.e., informants' perspective) instead of an etic perspective (i.e., predetermined factors by researchers). Ethnographic tools, such as the free listing method, CCA and CCoA were found to be useful in elucidating consumer-oriented trustworthiness factors. In addition, this study offered baseline insights for utilizing a cultural variable to extend an existing TAM model. The result confirmed that the link between a particular culture and individuals' actual behaviors constituted a significant antecedent to attitude towards the website, demonstrating the usefulness of cultural consonance, which is a concept that originated in cognitive anthropology.

This study offers practical implications to managerial teams for UGC websites. Overall, is important to make an effort to enhance the trustworthiness of a website. However, it would be more meaningful to segment their target consumers, and achieve a thorough understanding of culturally favored and disfavored trustworthiness factors for each subgroup. To do so, UGC website managers could administer a regular assessment of perceived trustworthiness factors, particularly among the segmented cultural group. Then, managers would need to support appropriate formats and functions to realize important trustworthiness factors, highlight them in writing, and arrange reviews. For example, one of the highly-ranked trustworthiness factors was whether a review includes points in which an individual is interested (e.g., cleanliness, accessibility). It would be desirable to ask reviewers to mark the key satisfaction points among the given multiple options and, at the same time, allow customers to filter 
the reviews based on their primary points of interest in accommodation selection. Such efforts would assist to enhance consumers' positive attitudes, as well as their continued use of a website.

Despite the merits of this study, it is not without limitations. First, since the sample was not randomly selected, the results might not be representative of all members in Generation Y. Moreover, small cities or rural areas were excluded in this study, although Internet use is nationwide and universal. Therefore, researchers should expand the target population to increase the level of representativeness in future research. Second, in this study, we examined cultural consensus of the importance of trustworthiness toward online hotel reviews for only one group: Generation Y. In future research, it would be useful to demonstrate cultural models of multiple groups by subculture, such as age, gender, or nationality, and make cross-cultural comparisons among them. Third, cultural consonance was calculated as a single value, indicating whether individual beliefs were in accordance with one's behaviors. It would be meaningful to segment items into multiple groups by their level of importance [57,59]. For example, if items were specified as items rated highest in importance, items rated next-highest in importance, and items rated lowest in importance, cultural consonance for each group may exert different influences on outcome variables.

Author Contributions: Conceptualization, S.Y.B. and J.H.H.; data collection, S.Y.B. and J.H.H.; data analysis, S.Y.B; writing-original draft preparation, S.Y.B. and J.H.H; writing—review and editing, S.Y.B. and J.H.H. All authors have read and agreed to the published version of the manuscript.

Funding: This research received no external funding.

Conflicts of Interest: The authors declare no conflict of interest.

\section{References}

1. Filieri, R.; McLeay, F. E-WOM and accommodation: An analysis of the factors that influence travelers' adoption of information from online reviews. J. Travel Res. 2014, 53, 44-57. [CrossRef]

2. Parra-López, E.; Bulchand-Gidumal, J.; Gutiérrez-Taño, D.; Díaz-Armas, R. Intentions to use social media in organizing and taking vacation trips. Comput. Hum. Behav. 2011, 27, 640-654. [CrossRef]

3. Davis, F.D. A Technology Acceptance Model for Empirically Testing New End-User Information Systems: Theory and Results. Ph.D. Thesis, Sloan School of Management, Massachusetts Institute of Technology, Cambridge, MA, USA, 1985.

4. Joo, J.; Sang, Y. Exploring Koreans' smartphone usage: An integrated model of the technology acceptance model and uses and gratifications theory. Comput. Hum. Behav. 2013, 29, 2512-2518. [CrossRef]

5. Kim, T.G.; Lee, J.H.; Law, R. An empirical examination of the acceptance behaviour of hotel front office systems: An extended technology acceptance model. Tour. Manag. 2008, 29, 500-513. [CrossRef]

6. Lee, H.Y.; Kim, W.G.; Lee, Y. Testing the determinants of computerized reservation system users' intention to use via a structural equation model. J. Hosp. Tour. Res. 2006, 30, 246-266. [CrossRef]

7. Beldad, A.D.; Hegner, S.M. Expanding the technology acceptance model with the inclusion of trust, social influence, and health valuation to determine the predictors of German users' willingness to continue using a fitness app: A structural equation modeling approach. Int. J. Hum. Comput. Int. 2018, 34, 882-893. [CrossRef]

8. Pavlou, P.A. Consumer acceptance of electronic commerce: Integrating trust and risk with the technology acceptance model. Int. J. Electron Comm. 2003, 7, 101-134.

9. Lai, P. Security as an extension to TAM model: Consumers' intention to use a single platform E-Payment. Asia Pac. J. Manag. Res. Innov. 2017, 13, 110-119. [CrossRef]

10. Filieri, R.; Alguezaui, S.; McLeay, F. Why do travelers trust TripAdvisor? Antecedents of trust towards consumer-generated media and its influence on recommendation adoption and word of mouth. Tour. Manag. 2015, 51, 174-185. [CrossRef]

11. Agag, G.M.; El-Masry, A.A. Why do consumers trust online travel websites? Drivers and outcomes of consumer trust toward online travel websites. J. Travel Res. 2017, 56, 347-369. [CrossRef]

12. Ayeh, J.K.; Au, N.; Law, R. Do we believe in TripAdvisor? Examining credibility perceptions and online travelers' attitude toward using user-generated content. J. Travel Res. 2013, 52, 437-452. [CrossRef] 
13. Casalo, L.V.; Flavian, C.; Guinaliu, M.; Ekinci, Y. Do online hotel rating schemes influence booking behaviors? Int. J. Hosp. Manag. 2015, 49, 28-36. [CrossRef]

14. Roberts, J.M. The self-management of cultures. In Explorations in Cultural Anthropology; Goodenough, W., Ed.; MacGraw-Hill: New York, NY, USA, 1964; pp. 433-454.

15. Romney, A.K.; Weller, S.C.; Batchelder, W.H. Culture as consensus: A theory of culture and informant accuracy. Am. Anthropol. 1986, 88, 313-338. [CrossRef]

16. Dressler, W.W. Cultural consonance: Linking culture, the individual and health. Prev. Med. 2012, 55, 390-393. [CrossRef] [PubMed]

17. Dressler, W.W.; Balieiro, M.C.; dos Santos, J.E. Cultural consonance in life goals and depressive symptoms in urban Brazil. J. Anthropol. Res. 2017, 73, 43-65. [CrossRef]

18. Dressler, W.W.; Balieiro, M.C.; Ribeiro, R.P.; Dos Santos, J.E. Cultural consonance and psychological distress: Examining the associations in multiple cultural domains. Cult. Med. Psychiatry 2007, 31, 195-224. [CrossRef]

19. Chick, G. Culture as a variable in the study of leisure. Leis. Sci. 2009, 31, 305-310. [CrossRef]

20. Sheahan, P. Generation Y: Thriving and Surviving with Generation Y at Work; Hardie Grant Books Prahran: Victoria, Australia, 2005.

21. Nusair, K.K.; Parsa, H.G.; Cobanoglu, C. Building a model of commitment for Generation Y: An empirical study on e-travel retailers. Tour. Manag. 2012, 32, 833-843. [CrossRef]

22. Benckendorff, P.; Moscardo, G.; Pendergast, D. Tourism and Generation Y; CAB International: Oxfordshire, UK, 2010.

23. Boyer, K.K.; Hult, G.T.M. Customer behavior in an online ordering application: A decision scoring model. Decis. Sci. 2005, 36, 569-598. [CrossRef]

24. De Pelsmacker, P.; Geuens, M.; Van den Bergh, J. Marketing Communicatie; Pearson Education Benelux: Amsterdam, The Netherlands, 2005.

25. Brosdahl, D.J.; Carpenter, J.M. Shopping orientations of US males: A generational cohort comparison. J. Retail. Consum. Serv. 2011, 18, 548-554. [CrossRef]

26. Prensky, M. Digital natives, digital immigrants. In Crosscurrents: Cultures, Communities, Technologies; Blair, K.L., Almjeld, J., Murphy, R.M., Eds.; Wadsworth Cengage Learning: Boston, MA, USA, 2001; pp. 45-51.

27. Lester, D.H.; Forman, A.M.; Loyd, D. Internet shopping and buying behavior of college students. Serv. Mark. Q. 2006, 27, 123-138. [CrossRef]

28. Sago, B. The influence of social media message sources on millennial generation consumers. Int. J. Integr. Mark. Commun. 2010, 2, 7-18.

29. Rapp, A.; Beitelspacher, L.S.; Grewal, D.; Hughes, D.E. Understanding social media effects across seller, retailer, and consumer interactions. J. Acad. Market. Sci. 2013, 41, 547-566. [CrossRef]

30. Mettler, L. Millennial Appeal: 5 Ways Hotels Are Angaging Generation Y. US News. Available online: http://travel.usnews.com/features/Millennial-Appeal-5-wayshotels-are-engaging-Gen-Y (accessed on 15 September 2015).

31. Djamasbi, S.; Siegel, M.; Tullis, T. Generation Y, web design, and eye tracking. Int. J. Hum-Comput. St. 2010, 68, 307-323. [CrossRef]

32. Petrak, N. Generation Y: Soon-to-be Your Next Best Customers. Available online: https://www. adventuretravelnews.com/generation-y-soon-to-be-your-next-best-customers. (accessed on 12 July 2011).

33. Farris, R.; Chong, F.; Danning, D. Generation Y: Purchasing power and implications for marketing. Acad. Mark. Stud. J. 2002, 6, 89-101.

34. Nusair, K.K.; Bilgihan, A.; Okumus, F.; Cobanoglu, C. Generation Y travelers' commitment to online social network websites. Tour. Manag. 2013, 35, 13-22. [CrossRef]

35. Bilgihan, A. Gen Y customer loyalty in online shopping: An integrated model of trust, user experience and branding. Comput. Hum. Behav. 2016, 61, 103-113. [CrossRef]

36. Bento, M.; Martinez, L.M.; Martinez, L.F. Brand engagement and search for brands on social media: Comparing Generations X and Y in Portugal. J. Retail. Consum. Serv. 2018, 43, 234-241. [CrossRef]

37. Johnson, T.J.; Kaye, B.K. In blog we trust? Deciphering credibility of components of the internet among politically interested internet users. Comput. Hum. Behav. 2009, 25, 175-182. [CrossRef]

38. Sarabia-Sánchez, F.J.; Rodríguez-Sánchez, C.; Hyder, A. The role of personal involvement, credibility and efficacy of conduct in reported water conservation behaviour. J. Environ. Psychol. 2014, 38, 206-216. [CrossRef] 
39. Abarbanel, B.; Bernhard, B.; Singh, A.K.; Lucas, A. Impact of virtual atmospherics and functional qualities on the online gambler's experience. Behav. Inform. Technol. 2015, 34, 1005-1021. [CrossRef]

40. Filieri, R. What makes an online consumer review trustworthy? Ann. Tour.Res. 2016, 58, 46-64. [CrossRef]

41. Cheung, M.Y.; Luo, C.; Sia, C.L.; Chen, H. Credibility of electronic word-of-mouth: Informational and normative determinants of on-line consumer recommendations. Int. J. Electron. Comm. 2009, 13, 9-38. [CrossRef]

42. Qiu, L.; Pang, J.; Lim, K.H. Effects of conflicting aggregated rating on eWOM review credibility and diagnosticity: The moderating role of review valence. Decis. Support Syst. 2012, 54, 631-643. [CrossRef]

43. Kusumasondjaja, S.; Shanka, T.; Marchegiani, C. Credibility of online reviews and initial trust: The roles of reviewer's identity and review valence. J. Vacat. Mark. 2012, 18, 185-195. [CrossRef]

44. Goodenough, W.H. Cultural Anthropology and Linguistics; Bobbs-Merrill: Indianapolis, IN, USA, 1957.

45. Boyd, R.; Richerson, P.J. The Origin and Evolution of Cultures; Oxford University Press: New York, NY, USA, 2005.

46. Borgatti, S.P.; Halgin, D.S. Elicitation techniques for cultural domain analysis. Ethnogr. Toolkit 1999, 3, $115-151$.

47. Barsalou, L.W. Ad hoc categories. Mem. Cognit. 1983, 11, 211-227. [CrossRef]

48. Collins, C.C.; Dressler, W.W. Cultural consensus and cultural diversity: A mixed methods investigation of human service providers' models of domestic violence. J. Mix. Method Res. 2008, 2, 362-387. [CrossRef]

49. Weller, S.C. Cultural consensus theory: Applications and frequently asked questions. Field Methods 2007, 19, 339-368. [CrossRef]

50. Caulkins, D.; Hyatt, S.B. Using consensus analysis to measure cultural diversity in organizations and social movements. Field Methods 1999, 11, 5-26. [CrossRef]

51. Snodgrass, J.G.; Dengah, H.F., II; Lacy, M.G.; Bagwell, A.; Van Oostenburg, M.; Lende, D. Online gaming involvement and its positive and negative consequences: A cognitive anthropological "cultural consensus" approach to psychiatric measurement and assessment. Comput. Hum. Behav. 2017, 66, 291-302. [CrossRef]

52. Fielding-Miller, R.; Dunkle, K.L.; Cooper, H.L.; Windle, M.; Hadley, C. Cultural consensus modeling to measure transactional sex in Swaziland: Scale building and validation. Soc. Sci. Med. 2016, 148, 25-33. [CrossRef] [PubMed]

53. Schrauf, R.W.; Sanchez, J. Using freelisting to identify, assess, and characterize age differences in shared cultural domains. J. Gerontol. Ser. B Psychol. Sci. Soc. 2008, 63, S385-S393. [CrossRef]

54. Ribeiro, N.F.; Yarnal, C.M. 'It wasn't my sole purpose for going down there'-An inquiry into the Spring Break experience and its relation to risky behaviors and alcohol consumption. Ann. Leis. Res. 2008, 11, 351-367. [CrossRef]

55. Kerstetter, D.L.; Bricker, K.S.; Li, H. Vanua and the people of the Fijian Highlands: Understanding sense of place in the context of nature-based tourism development. Tour. Anal. 2010, 15, 31-44. [CrossRef]

56. Bae, S.Y.; Chick, G. An emerging Korean youth culture, Rail-ro: The application of cultural consensus analysis to domestic rail travel experiences. Curr. Issues Tour. 2017, 20, 363-368. [CrossRef]

57. Chick, G.; Hsu, Y.C.; Yeh, C.K.; Hsieh, C.M.; Ramer, S.; Bae, S.Y.; Xue, L.; Dong, E. Cultural consonance mediates the effects of leisure constraints on leisure satisfaction: A reconceptualization and replication. Leis. Sci. 2018, 1-20. [CrossRef]

58. Chick, G.; Dong, E.; Iarmolenko, S. Cultural consonance in leisure activities and self-rated health in six cities in China. World Leis. J. 2014, 56, 110-119. [CrossRef]

59. Chick, G.; Hsu, Y.C.; Yeh, C.K.; Hsieh, C.M.; Bae, S.Y.; Iarmolenko, S. Cultural consonance in leisure, leisure satisfaction, life satisfaction, and self-rated health in urban Taiwan. Leis. Sci. 2016, 38, 402-423. [CrossRef]

60. Ajzen, I.; Fishbein, M. Understanding Attitudes and Predicting Social Behavior; Prentice Hall: Englewood Cliffs, NJ, USA, 1980.

61. Ayeh, J.K. Travellers' acceptance of consumer-generated media: An integrated model of technology acceptance and source credibility theories. Comput. Hum. Behav. 2015, 48, 173-180. [CrossRef]

62. Persico, D.; Manca, S.; Pozzi, F. Adapting the technology acceptance model to evaluate the innovative potential of e-learning systems. Comput. Hum. Behav. 2014, 30, 614-622. [CrossRef]

63. Morosan, C. Theoretical and empirical considerations of guests' perceptions of biometric systems in hotels: Extending the technology acceptance model. J. Hosp. Tour. Res. 2012, 36, 52-84. [CrossRef]

64. Ham, S.; Kim, W.G.; Forsythe, H.W. Restaurant employees' technology use intention: Validating technology acceptance model with external factors. J. Hosp. Leis. Mark. 2008, 17, 78-98. [CrossRef]

65. Amaro, S.; Duarte, P. An integrative model of consumers' intentions to purchase travel online. Tour. Manag. 2015, 46, 64-79. [CrossRef] 
66. Xie, Q.; Song, W.; Peng, X.; Shabbir, M. Predictors for e-government adoption: Integrating TAM, TPB, trust and perceived risk. Electron. Libr. 2017, 35, 2-20. [CrossRef]

67. Chircu, A.M.; Davis, G.B.; Kauffman, R.J. Trust, expertise and ecommerce intermediary adoption. In Proceedings of the Sixth Americas Conference on Information Systems, Long Beach, CA, USA, 10-13 August 2000; DeGross, J., Ed.; ACM: New York, NY, USA, 2000; pp. 710-716.

68. King, W.R.; He, J. A meta-analysis of the technology acceptance model. Inform. Manag. 2006, 43, 740-755. [CrossRef]

69. Weller, S.C.; Romney, A.K. Systematic Data Collection; Sage Publications: Newbury Park, CA, USA, 1988.

70. Schrauf, R.W.; Sanchez, J. Age effects and sample size in free listing. Field Methods 2010, 22, 70-87. [CrossRef]

71. Anderson, J.C.; Gerbing, D.W. Structural equation modeling in practice: A review and recommended two-step approach. Psychol. Bull. 1988, 103, 411-423. [CrossRef]

72. Campbell, D.T.; Donald, W.F. Convergent and discriminant validation by the multitrait-multimethod matrix. Psychol. Bull. 1959, 56, 81-105. [CrossRef]

73. Hair, J.F.; Black, W.C.; Babin, B.J.; Anderson, R.E. Multivariate Data Analysis; Pearson Prentice Hall: Upper Saddle River, NJ, USA, 2010.

74. Fornell, C.; Larcker, D.F. Evaluating structural equation models with unobservable variables and measurement error. J. Market. Res. 1981, 18, 39-50. [CrossRef]

75. Larsen, J. De-exoticizing tourist travel: Everyday life and sociality on the move. Leis. Stud. 2008, 7, 21-34. [CrossRef]

76. Merigo, J.M.; Palacios-Marques, D.; Zeng, S. Subjective and objective information in linguistic multi-criteria group decision making. Eur. J. Oper. Res. 2016, 248, 522-531. [CrossRef]

77. Sohaib, O.; Kang, K. Individual level culture influence on online consumer iTrust aspects towards purchase intention across cultures: A SOR model. Int. J. Electron. Bus. 2015, 12, 142-161. [CrossRef]

78. Thongpapanl, N.; Ashraf, A.R. Enhancing online performance through website content and personalization. J. Comput. Inform. Syst. 2011, 52, 3-13.

79. De Mooij, M.; Hofstede, G. The Hofstede model: Applications to global branding and advertising strategy and research. Int. J. Advert. 2010, 29, 85-110. [CrossRef]

80. Wu, M.Y.; Chou, H.P.; Weng, Y.C.; Huang, Y.H. TAM-2 based study of website user behavior-using web 2.0 websites as an example. WSEAS Trans. Bus. Econ. 2011, 4, 133-151.

(C) 2020 by the authors. Licensee MDPI, Basel, Switzerland. This article is an open access article distributed under the terms and conditions of the Creative Commons Attribution (CC BY) license (http://creativecommons.org/licenses/by/4.0/). 